\title{
A vigilância social na política de assistência social: uma aproximação conceitual
}

The social surveillance in the social work policy: a conceptual approach

\author{
Maria Luiza Amaral Rizzotti \\ Thaís Gaspar Mendes da Silva **
}

\begin{abstract}
Resumo:
O presente estudo tem como objetivo realizar uma reflexão inicial sobre o conceito de Vigilância Social, em função de sua inserção, de forma central, na Política de Assistência Social em vigor. O estudo aborda os conceitos de Vulnerabilidade Social, Risco Social e Território, pois estes estão postos na circunscrição do conceito de vigilância social, conforme texto normativo. O caminho reflexivo seguiu a lógica de apresentar, primeiramente, uma discussão teórica sobre conceito de vigilância, recorrendo à sua definição no campo da saúde pública. Apresenta, também, uma discussão sobre as orientações oficiais em relação à vigilância como elemento orientador para a operação do Sistema Único de Assistência Social (SUAS), além de um diálogo com autores que discutem os conceitos de Vulnerabilidade Social, Risco Social e Território - relacionados à Política de Assistência Social. As conclusões apontam que há necessidade de um aprofundamento sobre o tema, pois a vigilância é elemento impulsionador da necessária articulação entre a leitura socioterritorial e as funções protetivas previstas na operação da política em questão.
\end{abstract}

Palavras-chave: Vigilância social; Vulnerabilidade social; Risco social; território.

\begin{abstract}
:
This paper aims to conduct an initial approach to the concept of Social Watch, due to its insertion, so central in Social Assistance Policy in force. The study also discusses the concepts of Social Vulnerability, Risk and Social Planning in the district because they put the concept of social surveillance aimed at normative text. The reflective path followed the logic of presenting primarily a theoretical discussion of the concept of surveillance, using the definition of surveillance in the field of public health. Provides a discussion of the post in the official guidelines under the aegis of guiding element for the operation of the Unified Social Assistance System (ITS) and dialogue with authors who are discussing these concepts - Social Vulnerability, Risk and Social Territory related to Social Assistance Policy. The findings point towards further development of the theme as the stimulus to promote the necessary linkage between reading socioterritorial and functions set out in protective operation of policy on screen.
\end{abstract}

* Profa. Doutora em Serviço Social pela Pontifícia Universidade Católica de São Paulo. Docente da Universidade Estadual de Londrina - UEL - em nível de graduação e pós graduação. E-mail: marialuizarizzotti@gmail.com

** Assistente Social, Mestre em Serviço Social e Política Social pela Universidade Estadual de Londrina - UEL. Atualmente docente da Faculdade de Presidente Prudente - FAPEPE. E-mail: thagaspar@yahoo.com.br 
Keywords: Monitoring social. Vulnerability and social risk. Territory.

\section{Introdução}

No atual cenário nacional, o desenho institucional da Política de Assistência Social pauta-se no Sistema Único da Assistência Social (SUAS), que regula e organiza, em todo território nacional, serviços, programas, projetos e benefícios socioassitenciais, por meio de um sistema descentralizado e participativo. Esse sistema de caráter federalista, que vem sendo implantado há seis anos, supõe a habilitação de todos os municípios brasileiros, cujas responsabilidades são também atribuídas à gestão regional dos Estados, do Distrito Federal, além da União como instância federal (SPOSATI, 2001).

O Sistema Único de Assistência Social (SUAS) apresenta-se como uma das possibilidades reais de alargamento e ampliação dos direitos de proteção social não contributiva. Aprovado em 2005, o SUAS define e organiza os elementos essenciais e imprescindíveis à execução da política de assistência social, buscando, sob sua responsabilidade, dar respostas a três funções: Proteção Socioassistencial, Defesa Social e Institucional e Vigilância Social.

Na função Proteção Social, a política é hierarquizada entre proteção social básica e especial e estabelece as seguranças ou proteções que deverão ser afiançadas pela assistência social. Ela tem por direção o desenvolvimento humano e social e os direitos de cidadania. Para tanto, deve ser entendida como o conjunto de todos os serviços, programas, projetos e benefícios do SUAS que visam à "redução e prevenção do impacto das vicissitudes sociais e naturais ao ciclo da vida, à dignidade humana e à família como núcleo básico de sustentação afetiva, biológica e relacional” (BRASIL, 2005b, p. 19).

Por ter como direção o desenvolvimento humano e social e os direitos de cidadania, a proteção social de assistência social descreve como princípios: a matricialidade sociofamiliar; a territorialização; a proteção pró-ativa; a integração à seguridade social; e a integração às políticas econômicas e sociais (BRASIL, 2005b, p. 17).

A função de Defesa Social e Institucional deve estar organizada de forma a garantir aos usuários o acesso ao conhecimento dos direitos, bem como, sua defesa. Como constituinte do tripé da Seguridade Social, entende-se que a Política de Assistência Social deve se articular com outras políticas sociais que garantam direitos e condições dignas de 
vida a população. "Os direitos sociais devem estar presentes em todo o processo de implementação dos benefícios, serviços, programas e projetos socioassistenciais" e sob nenhuma hipótese o usuário deve ser submetido a relações de tutela e subalternização (BRASIL, 2008, p. 51).

A função de Defesa Social deve promover a ruptura da crença de que "para o pobre qualquer coisa serve", que o discrimina e o aparta do reconhecimento como sujeito de direitos. Desta forma, a consolidação do Sistema Único de Assistência Social exige que sua atuação circunscreva-se no campo dos direitos e não no campo do favor e que se consubstancie "a efetiva possibilidade de conhecimento e acesso dos usuários aos seus direitos e à sua fruição" (BRASIL, 2008, p. 53).

A Vigilância Social, terceira função definida pelo Sistema Único de Assistência Social, corresponde ao planejamento, produção, organização e sistematização de informações sobre a realidade socioterritorial, com o objetivo de identificar situações de vulnerabilidade e risco pessoal e social de famílias e indivíduos (BRASIL, 2004, 2005b) ${ }^{1}$.

Essas três funções - Proteção Socioassistencial, Defesa Social e Institucional e Vigilância Social "se inter-relacionam e se complementam no sistema descentralizado e participativo, construindo as referências centrais para a organização dos serviços socioassistenciais" (BRASIL, 2008, p. 50). Estas proporcionam condições reais para a ruptura com a cultura do imediatismo, da focalização e da fragmentação, tão necessárias à Política de Assistência Social, e para a definição do campo específico da responsabilidade pública da Assistência Social.

A Política Nacional de Assistência Social (PNAS), ao definir essas novas funções, inova ao conceituá-las e ao dar um significado para cada uma delas. Este estudo abordará, especificamente, uma dessas funções, a Vigilância Social, ação de responsabilidade do Estado, que nunca se fez presente na Política de Assistência Social, até a aprovação da Política Nacional de Assistência Social, em 2004, e a implantação do Sistema Único de Assistência Social, em 2005.

Para a discussão dessa função, este estudo apresenta, inicialmente, uma discussão sobre as bases conceituais que permeiam o tema em questão - Vulnerabilidade, Risco e

\footnotetext{
${ }^{1}$ A vigilância Social, ao ser definida como objeto de estudo desta pesquisa, possui título próprio, o que garante uma maior discussão dessa função da Política de Assistência Social.
} 
Território; em seguida, os aspectos do conceito de vigilância, tendo como base o campo da saúde pública, uma vez que o SUAS teve forte inspiração na lógica do Sistema Único de Saúde, incluindo semelhança de temas. Para concluir, apresenta a Vigilância Social à luz da Política de Assistência Social, de modo a analisar como esta orienta os processos de Vigilância Social, com ênfase na importância da gestão da informação enquanto alicerce fundamental para o exercício dessa função.

\section{As Bases Conceituais da Vigilância Social}

Ao se apresentar a Vigilância Social como Vigilância de Riscos e Vulnerabilidades, ou seja, enquanto "mecanismo essencial para a prevenção do risco, do quase risco e das situações de vulnerabilidades social existentes nos territórios e micro-territórios" (BRASIL, 2008, p. 51), é fundamental aprofundar a discussão sobre esses três conceitos-chave: vulnerabilidade social, risco e território, que constituem a base conceitual da Vigilância Social.

Esses conceitos possuem intrínseca relação com a vigilância social, uma vez que a ação desta se fundamenta em constantes estudos territorializados sobre diversas situações de vulnerabilidade e risco pessoal e social vividas por famílias/indivíduos. Assim, o aprofundamento desses conceitos é imprescindível para o aprimoramento da vigilância social adotada pela PNAS. É preciso discutir que vulnerabilidades e riscos são fatores presentes nos territórios que devem ser "cobertos" por uma Política de Proteção Social de Assistência Social.

Para a Política de Assistência Social, vulnerabilidade diz respeito a situações que podem levar à exclusão social de sujeitos, sejam elas originadas por processos de produção e reprodução de desigualdades sociais ou por processos discriminatórios, segregracionais, produzidos historicamente e socialmente, onde alguns grupos são privilegiados em detrimento de outros.

Logo, compreender as vulnerabilidades sociais significa entender a "mediação entre o acesso a direitos, rede de serviços e políticas públicas e a capacidade de sujeitos e grupos sociais de acessar esse conjunto de bens e serviços, exercendo a sua cidadania" (BRASIL, 2010, p. 76). Nesse sentido, conforme Bilac: 
As relações dos sujeitos, seja ela individual ou coletiva, com padrões de desenvolvimento geradores de desigualdade, tendem a produzir situações de fragilidades desses sujeitos, dos seus grupos de sociabilidade e dos territórios onde se encontram inseridos. Essa perspectiva possibilita reconhecer a descontinuidade ou mesmo a ausência de investimento estatal nos territórios e nos indivíduos, bem como as situações de estigma e desamparo que engendram ou reforçam condições de fragilidade. Por outro lado, possibilita também a compreensão das capacidades e potencialidades dos sujeitos para enfrentar as situações de risco e exclusão decorrentes dessas inter-relações. (BILAC, 2007 apud BRASIL, 2010, p. 76).

É comum autores relacionarem o conceito de vulnerabilidade social apenas ao fator econômico, ou seja, à renda. Entretanto, como afirma Oliveira (1995), a vulnerabilidade não repousa só no econômico, ainda que este seja elemento indispensável, mas associa-se também ao processo de discriminação social, que tem no mercado seu maior fomentador. O autor afirma que, quando se trata de políticas sociais públicas, para que essas atinjam seus objetivos, é preciso antes de tudo situá-las no campo do direito, retirando-as da conceituação de carências.

Ao se referirem à vulnerabilidade social, Mestriner e Nery (2009) apontam-na como "um conceito multifacetado com várias dimensões, que identificam situações vulneráveis de indivíduos, famílias e coletividades, sejam elas referentes aos contextos sóciodemográficos, de bens materiais e/ou afetivo-relacionais." Para as autoras, "estar em vulnerabilidade social significa ter a potencialidade de resposta alterada ou diminuída frente às situações de risco ou a constrangimentos naturais da vida". Assim, as vulnerabilidades "não prevenidas, não reduzidas e não corrigidas levam a riscos sociais que ampliam a exclusão e a pobreza."

Nessa mesma lógica, Paulilo e Jeolás (2000) apontam que a "vulnerabilidade não é uma essência ou algo inerente a algumas pessoas e grupos, mas diz respeito a determinadas condições e circunstâncias, que podem ser minimizadas ou revertidas." As autoras colocam a vulnerabilidade sob três vertentes: a social, a programática ou institucional e a individual. No plano social, incluem: as condições socioeconômicas; o acesso à informação; a escolarização; a garantia de acesso a serviços de saúde; a garantia de respeito aos direitos humanos; e a situação sociopolítica e cultural. O plano programático ou institucional compreende: a ofertadas de serviços, programas, projetos e atividades pelo Estado à população. O plano individual diz respeito à adoção de 
comportamentos seguros, plano este que depende, justamente, da inter-relação com os dois primeiros.

Conforme a PNAS, os eventos que vulnerabilizam as pessoas não são apenas determinados por aspectos de natureza econômica, pois outros fatores podem ser geradores de enfraquecimento de grupos ou indivíduos, entre eles, a subjetividade, pois nem sempre os indivíduos conseguem lidar com conflitos, perdas, rupturas, morte, separação, dentre outras situações (OLIVEIRA, 1995).

Desse modo, percebe-se que a Política de Assistência Social compreende o aspecto multidimensional presente no conceito de vulnerabilidade social, não o restringindo à percepção de pobreza, ou seja, à falta de recursos financeiros. "Fatores como a fragilização dos vínculos afetivo-relacionais e de pertencimento social (discriminações etárias, étnicas, de gênero ou por deficiência) ou vinculadas à violência, [...] à representação política, dentre outros, também afetam as pessoas", ou seja, também as vulnerabilizam (ALMEIDA, 2006).

O segundo conceito base que precisa ser aprofundado para o estudo da vigilância social é o de risco social. Esse conceito, assim como os demais - vulnerabilidade e território - possui intrínseca relação com o tema da vigilância, pois se dá no âmbito do território e perpassa um processo que visa a impedir os agravos da vulnerabilidade que levam ao risco e, consequentemente, à perda de mais direitos.

Para a Política Nacional de Assistência Sócia, o risco social não significa somente o perigo imediato, mas uma condição social que interfere na futura situação de um indivíduo ou coletividade. Prevenir o risco social, na atual conjuntura da Política de Assistência Social, é um direito do indivíduo e uma responsabilidade do Estado, preconizados como eixo da mesma.

Contudo, é importante estar atento à definição de risco social. É preciso diferenciar a noção de risco social utilizada pela Política de Assistência Social e a "das teses que intitulam a sociedade moderna como 'sociedade do risco', em função do alto grau de incerteza que comanda o futuro da civilização" (COUTO; YAZBEK; RAICHELIS, 2010, p. 53).

O risco social, que a vigilância social é responsável por detectar e informar as características e dimensões, engloba as contingências a que estão expostos indivíduos, famílias, classes sociais e coletividades que se encontram fora do alcance da rede de segurança propiciada pela proteção social pública e que são gerados por uma cadeia 
complexa de fatores. Logo, não se trata de uma imprevisibilidade a que todos os cidadãos de uma sociedade estão sujeitos, que gera um sentimento de impotência e uma "inflação atual da sensibilidade aos riscos que faz da segurança uma busca sem fim e sempre frustrada" (CASTEL, 2005 apud COUTO, YAZBEK, RAICHELIS, 2010, p. 53).

De acordo com Sposati (2001, p. 69), "as culturas liberal e neoliberal entendem o risco como uma questão de preocupação individual e pessoal" e reproduzem o discurso de que as incertezas da vida "devem ser enfrentadas e respondidas por cada um, de acordo com suas possibilidades". Nas políticas sociais, considerar a perspectiva da responsabilização individual para enfrentar riscos sociais que são societários, acaba por fortalecer políticas de proteção social focalizadas nos mais pobres ao invés de políticas universais (COUTO, YAZBEK, RAICHELIS, 2010). Ademais, não se rompe o circuito de 'sociedade de risco', quando o trabalhador é quem deve ser o provedor da superação do risco.

\footnotetext{
A segurança é uma exigência antropológica de todo indivíduo, mas sua satisfação não pode ser resolvida exclusivamente no âmbito individual. É também uma necessidade da sociedade que se assegure determinada medida a ordem social e se garanta uma ordem segura a todos seus membros. As políticas sociais representam um dos instrumentos especializados para cumprir essa função (VILALOBOS, 2000 apud SPOSATI, 2001, p. 70).
}

O terceiro e último conceito definido como base conceitual da Vigilância Social é o de território. A produção de informações entre as necessidades da população (demanda) e a oferta dos serviços, na perspectiva do território, constitui um dos eixos do sistema de Vigilância Social. É a partir do território que os dados são "colhidos" e, após sistematizados e analisados, auxiliam nas atividades de planejamento e avaliação dos próprios serviços. De tal modo, é impossível deixar de atrelar Vigilância Social e território.

A perspectiva de território adotada pelo SUAS interpreta a cidade com significado vivo, a partir dos autores que dela se utilizam (SANTOS; SILVEIRA, 2010). Essa análise, desenvolvida pelo geógrafo Milton Santos, permite que se compreenda:

[...] a forma como as relações sociais se materializam num dado espaço, conformando em um local específico as estruturas de oportunidade e ambientes de exposição a riscos, fazendo emergir na análise as potencialidades e vulnerabilidades próprias da dimensão territorial. Isto significa dizer que as potencialidades ou vulnerabilidades de uma mesma família ou indivíduo podem apresentar variações significativas, conforme o território em que está inserida. 
Como consequência desta perspectiva, o território em si, também deve ser encarado como objeto de intervenção/atuação da política de Assistência Social, para além das ações desenvolvidas com as famílias e indivíduos (SANTOS apud BRASIL, 2010, p. 74).

Nesse contexto, a perspectiva territorial, na esfera da Política Nacional de Assistência Social:

[...] tem representado um esforço coletivo pela perspectiva de uma política social mais comprometida com os chãos das cidades brasileiras". Coloca-se para a gestão desta política o desafio de "sair da constatação da importância do território no desenho da assistência social para sua incorporação no cotidiano da gestão (KOGA, 2003, p. 41).

Para a autora, o desvelamento desse desafio iniciou sua trajetória no momento em que a Política Nacional de Assistência Social introduziu as escalas de tamanho populacional para os municípios, o que, além de diferenciá-los por porte para a gestão dos serviços, norteiou também os novos parâmetros para o financimento da política.

Para Couto, Yazbek e Raichelis (2010, p. 50), "o território é o terreno das políticas públicas, onde se concretizam as manifestações da questão social e se criam os tensionamentos e as possibilidades para seu enfrentamento." A apropriação da perspectiva territorial, na gestão de políticas sociais, pode se constituir num instrumento fortalecedor da democratização, pois permite o conhecimento objetivo das diferenças de acesso, a partir de condições concretas, principalmente, em contextos de desigualdade. Dessa maneira, "ao considerar a possibilidade da gestão territorial como instrumento de democratização é preciso entender o território como um espaço dinâmico de relações onde necessidades e possibilidades se confrontam no cotidiano" (SPOSATI, 2008, p. 1).

Para um projeto de sociedade democrática, conforme aponta Koga (2003, p. 20), “o território é considerado como um dos elementos potenciais para uma nova perspectiva redistributiva possível para orientar políticas públicas". Essa proposta traz, em seu bojo, a preocupação com o protagonismo dos moradores, assim como, sua inclusão nos debates sobre: a organização dos espaços territoriais; a questão da cidadania; a dimensão cultural; e as particularidades locais. Esse conhecimento possibilita levantar, além das vulnerabilidades, também as potencialidades do lugar, para futuros fomentos com a participação dos sujeitos sociais. 
É evidente que a simples presença de políticas públicas não é o suficiente para a resolução da questão da exclusão social, pois é preciso considerar a forma como essa política opera. Para tanto, há que se levar em conta a cultura e a geografia da própria população - geografia humana - com a qual se trabalha (KOGA, 2003).

Não há dúvida de que o território é um espaço de disputa pelo uso e um importante instrumento que potencializa direitos. Contudo, algumas questões devem ser colocadas para debate e trabalhadas como centrais para que o território, como elemento inovador, não represente uma armadilha (COUTO; YAZBEK; RAICHELIS, 2010). Entre as ações que devem ser implementadas, destacam-se:

- reforçar os territórios homogêneos de pobreza: Apesar das políticas sociais elencream o trabalho na perspectiva do território, também se faz necessária a presença de uma estratégia global, com o objetivo de se evitar o reforço de divisões e desigualdades existentes entre os diferentes territórios de uma cidade. Muitas vezes, ao abordar o território e denominá-lo de "território vulnerável", reforça-se a perspectiva de territórios homôgeneos de pobreza e fomenta-se estigmas e imagens negativas por parte da sociedade e da própria população que vive no local. Além disso, a presença de uma estratégia global possibilita a articulação entre os territórios e traz consigo a demanda premente de um diagnóstico sólido e igualmente articulado sobre os mesmos, que permite relacionar cada um deles com outras faces da cidade e, ao mesmo tempo, com o projeto global. Não bastam referências detalhadas ou fotografias generalistas que demonstrem as características de cada território, pois uma visão de totalidade é fundamental para a compreensão das relações sociais (COUTO; YAZBEK; RAICHELIS, 2010; KOGA, 2002).

- Atrelar ao território todas as vulnerabilidades sociais: Apesar de algumas vulnerabilidades sociais estarem ligadas diretamente ao território, não se pode esquecer que "grande parte das vulnerabilidades sociais dos usuários da política de assistência social, não tem origem na dinâmica local, mas em processos estruturais." Não "enxergar" a totalidade é negar que os rumos da política econômica e de sua desvinculação da politica social, a precarização e a insegurança do trabalho, o enfraquecimento das instituições de proteção social, o retraimento do Estado e das políticas sociais, a incerteza e a insuficiência do orçamento para a proteção social e a baixa cobertura dos programas, serviços e 
benefícios afetam, diretamente, todos os cidadãos do país, principalmente, aqueles que mais demandam por proteção social.

Assim, a vigilância social pode refletir a proteção ou a desproteção social, pois a oferta de serviços sociais e a garantia das seguranças (direitos) de proteção social não dependem, única e exclusivamente, do território. Nesse sentido, a proteção ou desproteção refletem também a dinâmica global, seja ela do municipio, do estado, do país ou, até mesmo, do mundo.

Esses "cuidados", no que tange à utilização da perspectiva territorial, precisam ser bastante discutidos, no âmbito da Politica de Assistência Social, tendo em vista que a oferta de serviços com base nos territórios, defendida pela Política Nacional de Assistência Social, vem sendo incorporada por gestões municipais de assistência social de todo o país, e essa incorporação não pode, como defendem Couto, Yazbek e Raichelis (2010), transformar-se em uma armalhadilha, ao invés de apresentar o caráter inovador que a pressupõe.

\section{A vigilância na política de saúde: aproximações conceituais e operacionais com a vigilância social na política de assistência social}

Para melhor entendimento acerca do tema, além da definição dada pela Política Nacional de Assistência Social, é importante conhecer o conceito de vigilância proposto pela Política de Saúde, que há muito tempo já o utiliza para designar algumas funções no campo da saúde pública. A opção pelo estudo do significado de vigilância, na Política de Saúde, justifica-se, uma vez que sua utilização é antiga na área da saúde pública, pois data do século XIX. Além disso, a estrutura do modelo do SUAS, inspirada no SUS, aponta para a possibilidade de também ter havido uma importação desse conceito.

Dessa forma, as produções teóricas sobre vigilância no campo da Saúde, com a definição de conceito, objetivos e ações operacionais, auxiliam e subsidiam as análises da Vigilância Social na Política de Assistência Social, permitindo a indicação de aspectos semelhantes e/ou divergentes entre ambas as Políticas Públicas, no tocante à vigilância. Além disso, a produção bibliográfica e técnica, na área da Política de Assistência Social, no que diz respeito ao tema estudado, é bastante escassa.

Historicamente, a vigilância, na área de Saúde, "está relacionada aos conceitos de saúde e doença presentes em cada época e lugar, às práticas de atenção aos doentes e aos 
mecanismos adotados para tentar impedir a disseminação das doenças" (MONKEN; BATISTELLA, 2011).

Até meados do século $X X$, a saúde pública dispunha de poucos instrumentos para o controle de doenças. Dentre eles, os mais utilizados eram o isolamento e a quarentena, que surgiram no "final da Idade Média e consolidaram-se nos séculos XVII e XVIII com o início do desenvolvimento do comércio e da proliferação de centros urbanos," Entretanto, "na segunda metade do século XIX, com o rápido crescimento das atividades comerciais, efetuadas principalmente através dos portos e com o risco cada vez maior e mais frequente de ocorrência de epidemias", as dificuldades para a contenção de doenças se acentuaram (WALDMAN; ROSA, 1998, p. 16).

Neste mesmo período, com o avanço das investigações no campo das doenças infecciosas e o advento da bacteriologia, surge a estruturação de ações que visam à promoção da saúde, antes mesmo da ocorrência das doenças. Essas novas práticas, consideradas mais eficazes no controle das doenças, alteraram a forma de organização de serviços e ações em saúde coletiva no país (BRASIL, 2005a). A partir de então, surge, no campo da saúde pública, o conceito de "vigilância", como a "função de observar contatos de pacientes atingidos pelas denominadas doenças pestilências." No Brasil, os termos utilizados em saúde pública com esse significado foram: vigilância médica e, posteriormente, vigilância sanitária (WALDMAN; ROSA, 1998, p. 16).

\footnotetext{
A partir da década de 1950, o conceito de vigilância utilizado no campo da saúde deixa de ser aplicado no sentido da "observação sistemática de contatos de doente" e passa a possuir um significado mais amplo, o de "acompanhamento sistemático de eventos adversos à saúde na comunidade", com o propósito de aprimorar as medidas de controle (MONKEN; BATISTELLA, 2011, p. 1).
}

Atualmente, a aplicação da vigilância, no campo da saúde pública, incorpora "uma visão mais abrangente desse instrumento, com recomendações para a sua utilização não só em doenças transmissíveis, mas também em outros eventos adversos à saúde." Essa mudança se deu a partir da década de 1970, em virtude da realização da 21a Assembleia Mundial de Saúde, ocorrida em 1968, que promoveu ampla discussão a respeito da aplicação da vigilância no campo da saúde pública (WALDMAN; ROSA, 1998, p. 92).

Como principais objetivos da vigilância em saúde, os autores destacam: 
- Identificar novos problemas de saúde pública;

- Detectar epidemias;

- Documentar a disseminação de doenças;

- Estimar a magnitude da morbidade e mortalidade causadas por determinados agravos;

- Identificar fatores de risco que envolvem a ocorrência de doenças.

- Recomendar, com bases objetivas e científicas, as medidas necessárias para prevenir ou controlar a ocorrência de específicos agravos à saúde;

- Avaliar o impacto de medidas de intervenção por meio de coleta e análise sistemática de informações relativas ao específico agravo, objeto dessas medidas;

- Avaliar a adequação de táticas e estratégias de medidas de intervenção, com base não só em dados epidemiológicos, mas também nos referentes à sua operacionalização;

- Revisar práticas antigas e atuais de sistemas de vigilância com o objetivo de discutir prioridades em saúde pública e propor novos instrumentos metodológicos (WALDMAN; ROSA, 1998, p. 94-95).

Ao se analisar, brevemente, o significado de vigilância aplicado ao campo da saúde, percebe-se que o conceito utilizado, na atualidade, apresenta, obrigatoriamente, três componentes: coleta de dados; análise; ampla distribuição das informações analisadas a todos que as geraram e aos que delas necessitam tomar conhecimento. Essa compreensão assemelha-se ao entendimento proposto pela Vigilância Social da Política de Assistência Social, que tem, como responsabilidade principal, a produção, sistematização e análise de informações territorializadas sobre as situações de risco e vulnerabilidade que vivenciam famílias e indivíduos, assim como, de informações relativas ao tipo, volume e padrões de qualidade dos serviços ofertados pela rede socioassistencial. O que os difere, assim, é a distribuição das informações analisadas no âmbito da saúde, que não aparece, de maneira explícita, na assistência social. Entretanto, esta se faz presente quando a PNAS (BRASIL, 2004), ao se referir ao Centro de Referência da Assistência Social e aos serviços de proteção básica, aponta que é de responsabilidade da equipe do CRAS manter "ativo serviço de vigilância da exclusão social na produção, sistematização e divulgação de indicadores da área de abrangência do CRAS, em conexão com outros territórios" (BRASIL, 2004, p. 29). Desse modo, no âmbito da assistência social, também se deve produzir e disseminar informações e conhecimentos que contribuam para a efetivação do caráter preventivo e proativo da política da mesma.

Há outras semelhanças entre os objetivos da vigilância em saúde e da vigilância social, na assistência social, como apontam Waldman e Rosa (1998). Para os autores, a vigilância, na saúde, é: 
[...] entendida como um pré-requisito para a elaboração de programas de saúde e um instrumento para avaliação do seu impacto, e como meio para a identificação dos fatores de risco e das populações vulneráveis à exposição ao risco, de forma a tornar mais efetivas as medidas de controle (WALDMAN; ROSA, 1998, p. 96).

Nesse sentido, a Política de Assistência Social entende a vigilância social como "área de gestão da informação dedicada a apoiar as atividades de planejamento, supervisão e execução dos serviços socioassistenciais", o que a coloca como mecanismo necessário para a elaboração de programas sociais e, até mesmo, para a avaliação da atuação dos serviços sociais. A PNAS também elenca a vigilância social como responsável pela identificação de "situações de vulnerabilidade e risco pessoal e social que incidem sobre famílias/pessoas nos diferentes ciclos de vida (crianças, adolescentes, jovens, adultos e idosos)", com o objetivo traçar melhores ações e estratégias para prevenção e para redução de agravos (BRASIL, 2005b, p. 39).

É importante esclarecer que, no campo da saúde, a identificação dos fatores de risco e das populações vulneráveis tem o objetivo de tornar mais efetivas as medidas de controle, não dos usuários, mas de eventos adversos à saúde. Do mesmo modo, a assistência social deve identificar situações que vulnerabilizam famílias/pessoas e criar estratégias para a prevenção e a redução desses agravos. Essa ação pode ser entendida como controle, entretanto, não no sentido de vigiar a vida das famílias atendidas, como, por exemplo, como elas gastam o recurso do Benefício de Prestação Continuada (BPC) ou a Bolsa Família.

É imprescindível não entender como pressuposto da vigilância, em ambas as áreas, saúde e assistência social, apenas a coleta e a análise das informações. No caso da saúde, consiste em elaborar, "com fundamento científico, as bases técnicas que guiarão os serviços de saúde na elaboração e implementação dos programas de saúde com a preocupação de uma contínua atualização e aprimoramento" (WALDMAN; ROSA, 1998, p. 95). Na assistência social, além da coleta de dados, os serviços devem ser consumidores das informações processadas ou produzidas pela área de Vigilân cia Social. Tal fato contribui para avaliação de sua própria atuação e para a ampliação do conhecimento sobre as características da população e do território, visando a melhor atender às necessidades e demandas existentes e a desenvolver o planejamento e a execução de ações que 
assegurem oferta de serviços e benefícios às famílias e indivíduos mais vulneráveis, superando a atuação pautada, exclusivamente, na demanda espontânea.

Em síntese, pode-se afirmar que a criação do sistema de Vigilância Social colabora para que todos os objetivos do Sistema Único de Assistência Social sejam alcançados, o que, igualmente, ocorre na saúde. A existência dos sistemas de vigilância (sanitária, epidemiológica ambiental e nutricional) possibilita à saúde a garantia da "assistência às pessoas por intermédio de ações de promoção, proteção e recuperação da saúde, com a realização integrada das ações assistenciais e das atividades preventivas" (BRASIL, 1990). $\mathrm{Na}$ assistência social, a vigilância social possibilita elencá-la como sistema de monitoramento e prevenção de riscos, pois, a partir do diagnóstico territorial, é possível desenvolver uma gestão dos serviços de acordo com a demanda e as potencialidades da população.

A atual conjuntura capitalista (desigual, exploradora, devastadora etc.) leva à exclusão social dos cidadãos, por processos de produção e reprodução das desigualdades sociais ou discriminatórios e segregacionais. Desse modo, vigiar a vulnerabilidade enquanto aspecto social não é o mesmo que controlar pessoas vulneráveis. É preciso vigilância sobre as vulnerabilidades que atingem os cidadãos e não sobre as pessoas, vítimas de uma sociedade desigual e excludente.

\section{A vigilância social à luz da política de assistência social}

A Vigilância Social tem como função saber onde estão e quantos são os que demandam por proteção social e qual é a capacidade dos equipamentos e serviços para suprir suas necessidades. Nesse sentido, a Norma Operacional Básica do Sistema Único de Assistência Social (NOB/SUAS) define-a como "o desenvolvimento da capacidade e de meios de gestão assumidos pelo órgão público gestor da Assistência Social para conhecer a presença das formas de vulnerabilidade social da população e do território pelo qual é responsável." Isso significa que os responsáveis e operadores da Política de Assistência Social devem estar em alerta para "detectar e informar as características e dimensões das situações de precarização que vulnerabilizam e trazem riscos e danos aos cidadãos, a sua autonomia, socialização e ao convívio familiar" (BRASIL, 2005b, p. 20). Além disso, por meio 
da vigilância social, devem conhecer o território, intervir na realidade posta e planejar ações de prevenção e redução de vulnerabilidades e riscos sociais.

O estabelecimento da Política Nacional de Assistência Social da Vigilância Social, como função da Política de Assistência Social, trouxe uma nova concepção para a mesma, pois concebeu a Assistência Social como política pública de monitoramento e prevenção de riscos, a partir da leitura territorial, que possibilita a gestão dos serviços de acordo com a demanda e as potencialidades da população. Para cumprir seus objetivos, a Vigilância Socioassistencial:

\footnotetext{
- produz, sistematiza informações, constrói indicadores e índices territorializados das situações de vulnerabilidade e risco pessoal e social que incidem sobre famílias / pessoas nos diferentes ciclos de vida (crianças, adolescentes, jovens, adultos e idosos);

- identifica pessoas com redução da capacidade pessoal, com deficiência ou em abandono;

- identifica a incidência de crianças, adolescentes, jovens, adultos e idosos vítimas de formas de exploração, de violência, de maus tratos e de ameaças;

- identifica a incidência de vítimas de apartação social que Ihes impossibilite sua autonomia e integridade, fragilizando sua existência;

- exerce vigilância sobre os padrões de serviços de assistência social, em especial aqueles que operam na forma de albergues, abrigos, residências, semiresidências, moradias provisórias para os diversos segmentos etários (BRASIL, 2005b, p. 19-20).
}

Enquanto sistema de análise situacional de vulnerabilidade e risco social, a Vigilância Social constitui, atualmente, um instrumento de construção de saberes, o que supõe conhecimento da realidade, a partir da leitura das demandas, necessidades e potencialidades da população, e de monitoramento dos serviços de toda a rede de entidades de assistência social vinculadas ao Sistema Único de Assistência Social. O objetivo é construir uma rede local organizada de proteção social às famílias e indivíduos em situação de vulnerabilidade e risco pessoal ou social. Para tanto, a Vigilância Social possibilita:

[...] a instituição do processo sistemático do monitoramento no âmbito do sistema e a territorialização dos equipamentos de assistência social nas áreas de maior vulnerabilidade e risco, construindo assim a capilaridade da oferta de serviços socioassistenciais. O grande desafio posto é a implantação da Vigilância Social como estratégia fundamental para o reconhecimento e localização das vulnerabilidades e riscos, bem como, das violações de direito nos territórios, que oriente e avalie a oferta de serviços socioassistenciais de acordo com as necessidades de seus usuários (BRASIL, 2012, p. 8). 
Dessa forma, a Vigilância Social é condição imprescindível para que a Política de Assistência Social formule estratégias de intervenção social, com vistas à prevenção e ao monitoramento de riscos. Para tanto, a mesma é estruturada a partir de dois eixos: a Vigilância de Riscos e Vulnerabilidades e a Vigilância de Padrões e Serviços. A partir desses dois eixos, são articuladas, de um lado, as informações relativas à incidência de violações e à necessidade de proteção da população, e, de outro lado, as características e a distribuição da rede de proteção social instalada para a oferta de serviços (BRASIL, 2012).

A criação de um sistema de Vigilância Social, segundo a NOB/SUAS (BRASIL, 2005b), é de responsabilidade do órgão gestor municipal de Assistência Social, que deve enquadrálo na estrutura, em nível municipal, estadual e federal. É de competência da gestão a criação de uma metodologia de aplicação de indicadores para o diagnóstico dos contextos de vulnerabilidade e risco social, pois é este que subsidia o monitoramento da Política Municipal de Assistência Social. Entretanto, aos serviços da rede socioassistencial, dentre eles, os CRAS's, cabe a "alimentação" desse sistema por meio do fornecimento de informações e dados sobre as situações de vulnerabilidade, exclusão e risco social da população, obtidos por ações de vigilância social nos territórios referenciados.

Além disso, esses serviços, "devem ser consumidores das informações processadas e estruturadas" (BRASIL, 2010, p. 77). A utilização das informações possibilita a avaliação dos serviços, a ampliação do conhecimento sobre as características da população e do território e o planejamento do atendimento às necessidades e demandas existentes. Assim,

[...] a efetiva materialização da Vigilância Social, no sentido que Ihe atribui a PNAS, ocorre quando a gestão, o planejamento e execução dos serviços são orientados por uma perspectiva de produção e utilização de informações objetivas acerca da realidade social, que permite qualificar tecnicamente a tomada de decisões, sem, contudo, negar a importância do conteúdo político e social das escolhas e ações realizadas pelos gestores e profissionais (BRASIL, 2010, p. 77).

A construção do processo de Vigilância Social avança na definição de uma política de informação para o SUAS, considerando-se, para tanto, a tecnologia da informação enquanto alicerce fundamental. A instituição da Vigilância Social como uma área de gestão da informação, como ferramenta essencial para o planejamento, a supervisão e a execução dos serviços socioassistenciais, é um avanço de suma importância, pois a coleta de 
"evidências, orienta a organização da gestão e dos serviços, o processo de planejamento e a tomada de decisão" (BRASIL, 2010, p. 8). Nesse sentido, a vigilância social "pode e deve ser realizada com um sistema de informação" (MARTINS et al, 2008).

Contudo, no que diz respeito à Política de Assistência Social, enquanto política de informação para o SUAS, ainda existem algumas carências, entre elas, a ausência de sistemas de prontuário digital e a falta de padronização dos registros de atendimento dos serviços de assistência social.

As estruturas municipais de gestão, de modo geral, não possuem prontuários digitais para o cadastro de famílias atendidas. Comumente, os cadastros ou "fichas" são realizados de forma manual e não padronizada. De acordo com Martins et al (2008), o prontuário digital é instrumento de suma importância para a leitura de vulnerabilidades das famílias usuárias dos serviços sociais. Um sistema de cadastro deve revelar informações que demonstrem "quem são os usuários da política, quantos são, onde estão e em quais programas se encontram incluídos." Segundo as autoras, estas seriam as informações básicas necessárias para um cadastro digital. Além disso, outras informações, tais como as vulnerabilidades e potencialidades do usuário da política, de sua família e de seu território, também devem fazer parte dos registros eletrônicos. Desse modo, a ausência do uso da tecnologia da informação eleva o grau de dificuldade, o que se torna um empecilho para a sistematização, a análise e a produção de dados, ou seja, para a realização efetiva da Vigilância Social.

A segunda questão elencada para a qualificação da informação tem relação direta com a primeira, pois diz respeito à ausência de padronização dos instrumentos de registros de atendimentos de todos os serviços e da rede socioassistencial. Essa padronização é etapa imprescindível para a estruturação de uma base de dados para a Política de Assistência Social, que:

[...] a partir de questionários quantitativos e qualitativos, um documentomodelo" a ser utilizado em todos os atendimentos da área social, possibilitariam dados "mais consistentes e [...] maior será a probabilidade de contribuição com a qualidade dos serviços de assistência social (BRASIL, 2010).

No contexto da construção do processo de Vigilância Social, no âmbito da Política de Assistência Social, há, ainda, outro "problema" que a cerceia, ou seja, o não 
aprofundamento conceitual sobre a matéria em questão. Um exemplo disso pode ser vislumbrado neste estudo, quando, para a realização do mesmo, houve dificuldade devido à escassa produção bibliográfica disponível. Assim, para o aprimoramento conceitual do tema, seria necessária uma maior acuidade quanto a formulações teóricas sobre as bases conceituais que sustentam a Vigilância Social, tais como: território, risco e vulnerabilidade.

\section{Considerações finais}

Os conceitos de Vigilância Social apresentados pela Política Nacional de Assistência Social e pelo Sistema Único de Assistência Social abordam-na como "a produção e a sistematização de informações territorializadas sobre as situações de vulnerabilidade e risco que incidem sobre famílias e indivíduos" (BRASIL, 2010), ou seja, como estratégia para o conhecimento da realidade socioterritorial, cujos dados servem de subsídio para o desenvolvimento de ações com vistas à proteção social.

Esse conceito incorporado à Política de Assistência Social requer da comunidade científica uma análise e um aprofundamento de muitos aspectos que o envolvem e que necessitam de maior compreensão. Por se tratar de conteúdo novo para a Política de Assistência Social, é imprescindível, também, atentar para os equívocos de interpretação que podem permear o tema. A Vigilância Social jamais deve ser compreendida e executada como ferramenta de coerção e controle da população, como instrumento do Estado para vigiar, enquadrar e punir cidadãos.

Tal equívoco a respeito dos objetivos da Vigilância Social pode ser explicado, mas não justificado, quando sujeitos sociais não a compreendem como estratégia de conhecimento, de leitura territorial com o intuito desenvolver ações de proteção social, mas sob o prisma da vigilância sobre indivíduos. Entretanto, para que as pessoas cumpram normas, leis e regras, é necessário investimento em educação.

Assim, o uso da palavra vigilância, na expressão Vigilância Social ou Vigilância Socioassistencial, adotado pela Política de Assistência Social, pode conduzir a equívocos, tendo em vista que a Assistência Social foi construída, historicamente, permeada pelo caráter do não direito, dirigida aos pobres, a quem o Estado deveria controlar e não proteger. 
Desse modo, apesar dos avanços da Política de Assistência Social, no campo dos direitos, principalmente, após a aprovação do Sistema Único de Assistência Social, em 2005, a equívoca interpretação do conceito de Vigilância Social pode acarretar a punição daqueles a quem o Estado deveria proteger.

É importante, também, ressaltar outra discussão sobre as “imprecisões" da expressão vigilância social, que remete à recente alteração da redação da Lei Orgânica da Assistência Social, pela Lei. 12.435 de 2011. A partir dessa legislação, a função da Vigilância Social passa a ser considerada com base nos três objetivos da Política de Assistência Social:

Art. $2^{\circ}$ A assistência social tem por objetivos:

I - a proteção social, que visa à garantia da vida, à redução de danos e à prevenção da incidência de riscos, especialmente: a) a proteção à família, à maternidade, à infância, à adolescência e à velhice; b) o amparo às crianças e aos adolescentes carentes; c) a promoção da integração ao mercado de trabalho; d) a habilitação e reabilitação das pessoas com deficiência e a promoção de sua integração à vida comunitária; e e) a garantia de 1 (um) salário-mínimo de benefício mensal à pessoa com deficiência e ao idoso que comprovem não possuir meios de prover a própria manutenção ou de tê-la provida por sua família;

II - a vigilância socioassistencial, que visa a analisar territorialmente a capacidade protetiva das famílias e nela a ocorrência de vulnerabilidades, de ameaças, de vitimizações e danos;

III - a defesa de direitos, que visa a garantir o pleno acesso aos direitos no conjunto das provisões socioassistenciais.

Parágrafo único. Para o enfrentamento da pobreza, a assistência social realizase de forma integrada às políticas setoriais, garantindo mínimos sociais e provimento de condições para atender contingências sociais e promovendo a universalização dos direitos sociais. (BRASIL, 2011, p. 1).

A aprovação da nova redação da Lei Orgânica da Assistência Social é um avanço em relação à legalização do SUAS, pois a consistência desse constructo legal pode vir a dificultar os desmandos próprios das contrarreformas do Estado que atingem a Política de Assistência Social e sua "nova" organização político-institucional.

Contudo, no que se refere à Vigilância Social, a redação aprovada coloca como seu objetivo "analisar territorialmente a capacidade protetiva das famílias e nela a ocorrência de vulnerabilidades, de ameaças, de vitimizações e danos" (BRASIL, 2011, p. 1), e não a análise territorial da capacidade protetiva do Estado em relação às famílias dos territórios, o que parece mais correto. É tarefa do Estado identificar quem são e quantos são os que demandam por proteção social, assim como, a capacidade do Estado, via equipamentos sociais públicos, para responder às situações de vulnerabilidade e risco. Ao discutir a 
capacidade protetiva da família descolada da responsabilidade do Estado, pode-se incidir e reforçar resquícios de velhos paradigmas, historicamente, construídos na assistência social, que ganharam força com as políticas de cunho neoliberal.

Em relação ao aprimoramento conceitual, se faz necessária maior acuidade quanto às formulações teóricas das bases conceituais que sustentam a Vigilância Social, discutidas neste estudo: Vulnerabilidade, Risco e Território. Deve-se "buscar instituir uma abordagem específica para a produção de conhecimentos aplicados ao planejamento e desenvolvimento da política de assistência social" (BRASIL, 2010, p. 74).

Portanto, para que não ocorram equívocos sobre esses conceitos na política em questão, uma vez que os mesmos apresentam diferentes dimensões, nas mais diversas áreas de conhecimento, é necessário que a comunidade científica investigue e produza novos saberes no âmbito Política de Assistência Social. Embora inúmeros pesquisadores tenham se debruçado sobre o tema, há carência, principalmente, após a implantação do Sistema Único de Assistência Social, de estudos que abordem os fatores: vulnerabilidade, risco e território, que precisam ser, exaustivamente, debatidos e explorados. Somente quando houver maior clareza sobre a função da Vigilância Social, entendida como vigilância de prevenção de vulnerabilidades e riscos determinados socialmente dentro de territórios, será possível compreendê-la sob a lógica da garantia de direitos.

\section{Referências}

ALMEIDA, L. M. P. Vulnerabilidade social: desenvolvimento humano no Recife. 2006. Disponível em: <http://www.recife.pe.gov.br/pr/secplanejamento/pnud2006/doc/analiticos/Vulnerabilid ade\%20Social.pdf>. Acesso em: 4 jun. 2010.

BRASIL. Lei no 12.435, de 06 de julho de 2011. Altera a Lei no 8.742, de 07 de dezembro de 1993, que dispõe sobre a organização da Assistência Social. Disponível em: <http://www.planalto.gov.br/ccivil_03/_Ato2011-2014/2011/Lei/L12435.htm>. Acesso em: 5 jul. 2012.

Lei $n$ ‥ 8.080 de 19 setembro de 1990. Dispõe sobre as condições para a promoção, proteção e recuperação da saúde, a organização e o funcionamento dos serviços correspondentes e dá outras providências. Disponível em: <http://www.planalto.gov.br/ccivil_03/leis/l8080.htm>. Acesso em: 5 maio 2012. 
Ministério da Saúde. Secretaria de Vigilância em Saúde. Curso básico de vigilância epidemiológica. Brasília: Ministério da Saúde, 2005a.

Ministério de Desenvolvimento Social e Combate à Fome. Vigilância social. Disponível em: <http://www.mds.gov.br/assistenciasocial/vigi lancia>. Acesso em: 9 set. 2012.

Ministério do Desenvolvimento Social e Combate à Fome. Capacita SUAS: configurando os eixos de mudança. Brasília: Ministério de Desenvolvimento Social e Combate à Fome, 2008. v. 1.

Ministério do Desenvolvimento Social e Combate à Fome. Norma Operacional Básica do Sistema Único de Assistência Social (NOB/SUAS). Brasília: Ministério do Desenvolvimento Social e Combate à Fome, 2005b.

Ministério do Desenvolvimento Social e Combate à Fome. NOB SUAS 2010: aprimoramento da gestão e qualificação dos serviços socioassistenciais. Brasília, 2010. Disponível em: <http://www.mds.gov.br/.../nob-suas-2010-minuta-consulta-publicafinal.pdf >. Acesso em: 2 set. 2010.

Ministério do Desenvolvimento Social e Combate à Fome. Política nacional de assistência social (PNAS). Brasília: Ministério do Desenvolvimento Social e Combate à Fome, 2004.

COUTO. B. R.; YAZBEK, M. C.; RAICHELIS, R. A política nacional de assistência social e o SUAS: apresentando e problematizando fundamentos e conceitos. In: COUTO, B. R. et al. (Org.). O sistema único de assistência social no Brasil: uma realidade em movimento. São Paulo: Cortez, 2010. p. 32-65.

KOGA, D. Cidades entre territórios de vida e territórios vividos. Serviço Social e Sociedade, São Paulo, n. 72. p. 22-52, 2002.

Medidas de cidades: entre territórios de vida e territórios vividos. São Paulo: Cortez, 2003.

MARTINS, M. L. P. et al. Avaliação e monitoramento nas políticas sociais. Serviço Social em Revista, Londrina, v. 20, n. 2, jan./jul. 2008.

MESTRINER, M. L; NERY, V. Capacitação das entidades sociais de Campinas: questão social: vulnerabilidades e riscos sociais, PNAS e SUAS. 2009. Disponível em: <http://2009.campinas.sp.gov.br/.../vulnerabilidade_risco_campinas.pps>. Acesso em: 28 mar. 2010.

MONKEN, M.; BATISTELLA, C. Vigilância em saúde. Disponível em: <http://www.epsjv.fiocruz.br/dicionario/verbetes/vigsau.html>. Acesso em: 3 maio 2011. OLIVEIRA, F. A questão do estado: vulnerabilidade social e carência de direitos. Subsídios a I Conferência Nacional de Assistência Social. Cadernos ABONG, São Paulo, 1995. 
PAULILO, M. A S.; JEOLÁS, L.S. Jovens, drogas, risco e vulnerabilidade: aproximações teóricas. Serviço Social em Revista, Londrina, v. 3, n. 1, jul./dez. 2000.

SANTOS, M.; SILVEIRA, M. L. O Brasil: território e sociedade no início do século XXI. 13. ed. Rio de Janeiro: Record, 2010.

SPOSATI, A. Desafios para fazer avançar a política de assistência social no Brasil. Revista Serviço Social e Sociedade, São Paulo, n. 68, p. 54-82, nov. 2001.

Territorialização e desafios à gestão pública inclusiva: o caso da assistência social no Brasil. In: CONGRESSO INTERNACIONAL DEL CLAD SOBRE LA REFORMA DEL ESTADO Y DE LA ADMINISTRACIÓN PÚBLICA, 13., 2008, Buenos Aires. Anais... Buenos Aires, 2008. Disponível em:

<http://www.planejamento.gov.br/hotsites/seges/clad/documentos/sposati.pdf>. Acesso em: 8 out. 2009.

WALDMAN, E. A.; ROSA, T. E. Vigilância em saúde pública. Saúde e Cidadania, São Paulo, v. 7, 1998. Disponível em:

<bvsms.saude.gov.br/bvs/publicacoes/saude_cidadania_volume07.pdf>. Acesso em: 10 fev. 2011.

Recebido em: 12/02/2013

Aprovado em: 11/04/2013 